\title{
Diurnal Oscillation of the Convective Boundary Layer Part 1: Cloud-free Atmosphere
}

\author{
CHING-CHI Wu \\ Department of Atmospheric Sciences \\ National Taiwan University, Taipei, Taiwan, R.O.C. \\ AND \\ WEN-YIH SUN \\ Department of Earth and Atmospheric Sciences \\ Purdue University, West Lafayetle, IN 47907, U.S.A. \\ (Received 21 March 1990; revised 15 May 1990)
}

\begin{abstract}
A simple one-dimensional ensemble average PBL model, including condensation, evaporation, atmospheric radiation, and the surface energy budget, is used to study the evolution of the planetary boundary layer in a cloud-free atmosphere. In this model, the turbulent kinetic energy $E$ is predicted by a prognostic equation. The length scale $(l)$ of Sun and Ogura, and Deardorff is modified; the eddy coefficient is proportional to $\sqrt{E} l$, as suggested by Deardorff; and the similary equations proposed by Businger et al. are used for the surface layer. In addition, the force restoring method is adopted to predict the surface temperature and an analogous method is used to calculate the surface soil moisture. The model is used to simulate the data of Wangara Day 33. The simulated results are in good agreement with both those observed and those produced by the other more complicated model.
\end{abstract}

\section{INTRODUCTION}

In recent years, many sophisticated models of the planetary boundary layer (PBL) have been developed. In Deardorff's three-dimensional model (1974a, b), a major portion of eddy flux is explicitly calculated and the subgrid-scale turbulence is modeled by a second-order closure approximation. A large amount of computing time and central memory is required in his experiment because of the very small space and time intervals required for both. Therefore, his subgridscale turbulence parameterization is very difficult to apply in a mesoscale model.

On the other hand, the one-dimensional higher-order ensemble average turbulence model for both cloud-free and cloudy planetary boundary layers has been studied by many people; for example, Yamada and Mellor (1975, 1979), . 
Zeman and Lumley (1976), Andre et al. (1978), Oliver et al. (1978), Sun and Ogura (1980), and Chen and Cotton (1983a, b). These higher-order models have provided valuable information about the PBL. Even though they require much less computing time and central memory than the subgrid-scale model, the equations in these high-order models are still quite complicated and difficult to be incorporate into a mesoscale model.

To simplify the second-order turbulence scheme, Deardorff (1980) assumes that the eddy-coefficient relations are valid for eddy fluxes in the subgrid-scale turbulence. Therefore, only one prognostic equation is required for the turbulent kinetic energy to solve for eddy fluxes. His basic equations are very similar to those of the "level 2.5" ensemble average turbulence scheme in Mellor and Yarnada (1977), except that the formulae of mixing length scale are different.

Using the level 2.5 scheme but with the observational length scale of ensemble turbulence (Caughey and Palmer, 1979), Sun and Chang (1986a) obtained realistic results when compared to the observed data and predictions by other higher-order schemes. Meanwhile, their model is simple enough to be incorporated into a turbulence-diffusion model (Sun and Chang, 1986b; Sun, 1989) used to study air pollution in a convective boundary layer (CBL). However, the lengh scale proposed by Caughey and Palmer (1979) is valid only in a cloudyfree convective atmosphere; hence, a different turbulence length based upon Sun and Ogura (1980) is used in this study.

The force restoring method (Deardorff, 1978; Bhumralkar, 1975; Blackadar, 1976 ) is adopted here to predict the ground surface temperature. This method does not require caluation of multiple soil layer temperatures, but can produce results comparable to those with multiple soil layers.

As indicated by Andre et al. (1978), few models can make straight forward simulations of both the day and night evolution of the planetary boundary layer. One reason for this is the difference between the CBL during the daytime and the nocturnal inversion during the night. The former is primarily controlled by the buoyant production of turbulent energy near the ground surface, while the latter is driven by both radiative transfer and turbulence. Another difficulty in the simulation of the nocturnal planetary boundary layer is the formulation of turbulence for a strongly stable thermal stratification (Wyngaard, 1975; Zeman and Lumley, 1978; Andre et al., 1978). Fortunately, the present model can simulated 48 hours of the Wangara Experiment without any difficulty.

Here, Sun and Chang's (1986a) PBL model is modified by incorporating radiation parameterization. Also, the force restoring method is used to calculate the surface soil temperature and moisture. The observed data in Day 33-35 of the Wangara Experiment (Clarke et al., 1971) are used to verify the new model under a clear sky. Furthermore, the numerical simulation of the diurnal variation of the cloud-topped $\mathrm{PBL}$ will be presented in the accompanying paper 
(Part II of the study). The results are comparable to those generated by other higher-order turbulence schemes and observations. This PBL parameterization has also been successsfully incorporated into the Purdue mesoscale model to study the diurnal variation of the dryline for the Great Plains (Wu and Sun, 1987), the cold air outbreak over the warm ocean (Sun and Hsu, 1988), and air mass modification over Lake of Michigan (Sun and Yilidrim, 1989).

\section{DESCRIPTIONS OF THE MODEL}

\section{a. Governing equations}

The governing equations for the mean variables in this one-dimensional model are:

$$
\begin{gathered}
\frac{\partial \bar{u}}{\partial t}=f \bar{v}-f \bar{v}_{g}+\frac{\partial}{\partial z}\left(-\overline{u^{\prime} w^{\prime}}\right) \\
\frac{\partial \bar{v}}{\partial t}=-f \bar{u}+f \bar{u}_{g}+\frac{\partial}{\partial z}\left(-\overline{v^{\prime} w^{\prime}}\right) \\
\frac{\partial \bar{\theta}_{e}}{\partial t}=\frac{\partial}{\partial z}\left(-\overline{w^{\prime} \theta_{e}^{\prime}}\right)+\frac{f \theta_{0}}{g}\left(\bar{v} \frac{\partial \bar{u}_{g}}{\partial z}-\bar{u} \frac{\partial \bar{v}_{g}}{\partial z}\right)-\bar{w} \frac{\partial \bar{\theta}_{e}}{\partial z}-\left(\frac{\bar{\theta}}{T}\right)\left(\frac{1}{\rho C_{p}} \frac{\partial F}{\partial z}\right), \\
\frac{\partial \bar{q}_{w}}{\partial t}=\frac{\partial}{\partial z}\left(-\overline{w^{\prime} q_{w}^{\prime}}\right)-\bar{w} \frac{\partial \bar{q}_{w}}{\partial z}
\end{gathered}
$$

where $u, v$, and $w$ are the velocity components along $x$ (eastward), $y$ (northward), and $z$ (upward) coordinates, respectively. Overbars denote the ensemble average and primes signify the turbulence fluctuations from the ensemble average. The Coriolis parameter, $f$, at Hay, Australia $\left(34^{\circ} 30^{\prime} \mathrm{S}, 144^{\circ} 56^{\prime} \mathrm{E}\right)$ is $8.26 \times 10^{-5} s^{-1}$. The pressure gradients in Eqs. (1) and (2) are represented by geostrophic winds $\bar{u}_{g}$ and $\bar{v}_{g}$. Terms $\overline{u^{\prime} w^{\prime}}$ and $\overline{v^{\prime} w^{\prime}}$ are components of Reynolds' stress tensor in the $x$ and $y$ direction.

In Eq. (3), $\theta_{0}=273 K$, the equivalent potential temperature, $\theta_{e}$, is defined as:

$$
\theta_{e}=\theta+\left(l_{v} / C_{p}\right)(\theta / T) q
$$

where $\theta$ is the potential temperature, $l_{v}$ is the latent heat of vaporization, $C_{p}$ is the specific heat at constant pressure, $T$ is the temperature, and $q$ is the specific humidity. For shallow convection without precipitation, $\theta_{e}$ is a semiconservative quantity since $\left(l_{v} / C_{p}\right)(\theta / T)$ is essentially a constant. In the advection terms, the horizontal gradients of $\theta_{e}$ are represented by the vertical gradients of $\bar{u}_{g}$ and $\bar{v}_{g}$ through the thermal wind relations. The radiative cooling or 
warming rate is represented by the radiative flux divergence $-\left(1 / \rho C_{p}\right)(\partial F / \partial z)$. The total radiative flux, $F$, is defined by $F=F^{\uparrow}-F^{\downarrow}$, where $F^{\uparrow}$. and $F^{\downarrow}$ represent upward and downward fluxes, respectively. The reference state air density is $\rho$, while $\overline{w^{\prime} \theta^{\prime}}$ is the equivalent potential temperature flux. In the moisture equation (4), the total specific humidity, $q_{w}=q+q_{l}\left(q_{l}\right.$ is the specific liquid water content), is also a semi-conservative quantity in the absence of precipitation.

\section{b. Turbulence parameterization}

The turbulent kinetic energy equation is:

$$
\frac{\partial \bar{E}}{\partial t}=\frac{g}{\theta_{0}} \overline{w^{\prime} \theta_{v}^{\prime}}-\overline{u^{\prime} w^{\prime}} \frac{\partial \bar{u}}{\partial z}-\overline{v^{\prime} w^{\prime}} \frac{\partial \bar{v}}{\partial z}-\frac{\partial}{\partial z}\left[\overline{w^{\prime}\left(E^{\prime}+p^{\prime} / \rho\right)}\right]-\varepsilon_{d}
$$

where $E^{\prime}=0.5\left(u^{\prime 2}+v^{\prime 2}+{w^{\prime}}^{2}\right)$ is the turbulent kinetic energy, and $\bar{E}$ is the ensemble average of $E^{\prime} . \varepsilon_{d}$ is the rate of dissipation. The detailed equations for eddy fluxes, transport terms, and dissipation are presented is Sun and Hsu (1988).

Following Sun and Ogura (1980), the mixing-length scale $l$ is determined as follows:

for unstable condition $\left(\overline{w^{\prime} \theta^{\prime}}>0\right)$,

$$
l=l_{u}=\frac{10 \kappa z}{1+\left(\kappa z / l_{0}\right)}
$$

where,

$$
l_{0}=0.05 \frac{\int_{0}^{z_{t}} \bar{E}^{\frac{1}{2}} z d z}{\int_{0}^{z_{\mathrm{t}}} \bar{E}^{\frac{1}{2}} d z},
$$

for neutral or stable conditions $\left(\overline{w^{\prime} \theta_{v}^{\prime}} \leq 0\right)$,

$$
l=\frac{1}{\frac{1}{l_{u}}+\frac{1}{l_{s}}}
$$

where,

$$
l_{s}=1.316 \bar{E}^{\frac{1}{2}}\left[\frac{g}{\theta_{0}} \frac{-\overline{w^{\prime} \theta_{v}^{\prime}}}{K_{h}}\right]^{-\frac{1}{2}},
$$

In Eq. (7), $\kappa$ is the von Karman's constant and is set to 0.35. In Eq. (8), $z_{t}$ is the height of the top of the model. Because the length scale for the unstable condition is a monotonically increasing function with height, an upper limit for 
$l$ is set at $530 \mathrm{~m}$ in comparison with Sun and Chang's results (1986a). It is noted that Eq. (10) is similar to that in Deardorff (1980), but the coefficient 0.76 is replaced by 1.316 and $\left(\partial \bar{\theta}_{v} / \partial z\right)$ by $\left(-\overline{w^{\prime} \theta_{v}^{\prime}} / K_{h}\right)$. The larger coefficient is suggested by Sun and Chang (1986b) in order to increase the diffusion at the inversion layer.

\section{c. Parameterization of radiation}

The parameterization of radiation follows Chen and Cotton (1983b). For the cloud-free conditions, Rodgers' (1967) parameterization for long-wave radiation, Yamamoto's (1962) parameterization for the absorption of short-wave radiation, and Stephens' method (Chen and Cotton, 1983b) for Rayleigh scattering are utilized. In contrast, for a cloudy atmosphere, Stephens' (1978) parameterization for long- and short-wave radiation are used.

\section{d. Ground surface soil temperature and moisture}

The equation for the surface soil temperature, $T_{g}$, following Bhumralkar (1975), Blackadar (1976), and Deardorff (1978) is given as following:

$$
\frac{\partial T_{g}}{\partial t}=-c_{1} \frac{H_{A}}{\rho_{s} c_{s} d_{1}}-c_{2} \frac{T_{g}-T_{2}}{\tau_{1}}
$$

The first term on the right hand side is the energy balance term; the second term is the restoring term; $\tau_{1}$ is the diurnal period; $\rho_{s}$ and $c_{s}$ are the density and specific heat of soil, respectively; and $d_{1}$ is a soil depth influenced by the diurnal temperature cycle, expressed by:

$$
d_{1}=\left(\kappa_{s} \tau_{1}\right)^{\frac{1}{2}}
$$

where $\kappa_{s}$ is soil thermal diffusivity. The values of $\kappa_{s}$ and $\left(\rho_{s} c_{s}\right)$ in this study are set at $0.004 \mathrm{~cm}^{-2} \mathrm{~s}^{-1}$ and $0.37 \mathrm{cal} \mathrm{cm}^{-3} \mathrm{~K}^{-1}$, as in Case 1 in Deardorff (1978). $T_{2}$ is the mean soil temperature for a layer of depth $\left(d_{2}\right)$ influenced by the annual temperature cycle. For the short-range study, $T_{2}$ can be treated as a constant and assumed to be the mean surface temperature of the previous 24 hours (Deardorff, 1978). Coefficients $c_{1}$ and $c_{2}$ are equal to $2 \pi^{1 / 2}$ and $2 \pi$, respectively. In Eq. (11), $H_{A}$ is the sum of energy fluxes at the surface soil. It included the long-wave radiation from the ground surface to the atmosphere, the surface sensible heat flux and latent heat flux, the short-wave radiative flux reaching the ground surface $\left(S^{\downarrow}\right)$, and the long-wave radiative flux from the atmosphere to the ground surface $\left(R_{L}^{\downarrow}\right)$. Unlike that specified by the bulk formula in Deardorff (1978), the surface sensible heat flux and latent heat flux 
are calculated by the similarity equations proposed by Businger et al. (1971). $S^{\downarrow}$ and $R_{L}^{\downarrow}$ are provided by the radiation parameterization described above.

As for the ground surface temperature, the ground surface soil moisture, $w_{g}$, is predicted by the equation (Deardorff, 1978):

$$
\frac{\partial w_{g}}{\partial t}=-c_{1}^{\prime} \frac{E_{g}-P_{g}}{\rho_{w} d_{1}^{\prime}}-c_{2}^{\prime} \frac{w_{g}-w_{2}}{\tau_{1}}, \quad 0 \leq w_{g} \leq w_{\max } .
$$

The first term on the right hand side is a moisture budget term; in which $\rho_{w}$ is the density of liquid water, $d_{1}^{\prime}$ is the depth to which the diumal cycle of soil moisture reaches, and $P_{g}$ is the precipitation. The second term is a restoring term; in which, $w_{2}$ is the average soil moisture over a depth $d_{2}^{\prime}$; below $d_{2}^{\prime}$ the moisture flux is negligible. When $w_{g}$ is greater than $w_{\max }$ (the maximum value of $w_{g}$ ), the precipitation reaching the surface is considered to be runoff. The coefficients $c_{1}^{\prime}$ and $c_{2}^{\prime}$ are functions of the properties of the soil, specified as following (Jackson 1973; Deardorff, 1978):

$$
c_{1}^{\prime}= \begin{cases}0.5, & r \geq 0.75 \\ 14-22.5(r-0.15), & 0.15<r<0.75 \\ 14, & r \leq 0.15\end{cases}
$$

and

$$
c_{2}=0.9
$$

with $d_{1}^{\prime}=10 \mathrm{~cm}$ and $d_{2}^{\prime}=50 \mathrm{~cm}$; where, $r=w_{g} / w_{\max }$.

The time rate equation for $w_{2}$ can be expressed as:

$$
\frac{\partial w_{2}}{\partial t}=-\frac{E_{g}-P_{g}}{\rho_{w} d_{2}^{\prime}}, \quad 0 \leq w_{2} \leq w_{\max }
$$

The variation of $w_{2}$ with time is very slow. The surface specific humidity, $q_{g}$, is specified (Deardorff, 1978) by

$$
q_{g}=\alpha^{\prime} q_{s}\left(T_{g}\right)+\left(1-\alpha^{\prime}\right) q_{a}
$$

where $q_{s}\left(T_{g}\right)$ is the saturated specific humidity at temperature $T_{g}$, and $q_{a}$ is the specific humidity at height $z_{a}$. The coefficient $\alpha^{\prime}=\min \left(1, w_{g} / w_{k}\right) ; w_{k}$ is the saturated ground surface soil moisture. Above $w_{k}$, the soil is considered to be saturated. The value of $w_{k}$ is set at 0.30 as used in Deardorff (1978).

\section{GRID ARRANGEMENT, BOUNDARY AND INITIAL CONDITIONS}

a. Grid arrangement 
There are 22 grid points in the $z$ direction. A staggered grid is used with the first moments defined at $25 \mathrm{~m}, 100 \mathrm{~m}, 200 \mathrm{~m}, \ldots \ldots, 1900 \mathrm{~m}, 2000 \mathrm{~m}$, and the second moments defined at $50 \mathrm{~m}, 150 \mathrm{~m}, 250 \mathrm{~m}, \ldots \ldots, 1950 \mathrm{~m}, 2050 \mathrm{~m}$.

\section{b. Boundary conditions}

The temperature and specific humidity at the surface are predicted by Eqs. (11) and (13), respectively. The similarity equations (Businger et al, 1971) are applied in the surface layer $(\leq 25 \mathrm{~m})$. At the top of the domain, all the turbulence variables and wind shears are set at zero; the moisture varies only due to vertical advection, and the temperature varies only due to vertical advection and radiative cooling or warming. The vertical gradients of moisture and temperature at the upper boundary are fixed at their initial values.

\section{c. Initial conditions}

As mentioned before, the Wangara data at 0900 EST on Day 33 were used for the initial conditions. This case was chosen partly to facilitate a direct comparison between the present results and the numerical results obtained by Deardorff (1974a, b), Yamada and Mellor (1975), Andre et al. (1978), and Chen and Cotton (1983a).

The moisture content of the soil was not measured during the Experiment, but the soil appeared very dry on Day 33-35 from visual observations (Clarke et $a l ., 1971$ ). Therefore, the initial value of $w_{g}$ is set as 0.01. Following Deardorff (1978), the value of 0.30 is chosen for $w_{k}$, and $w_{m a x}$ is set as $1.33 w_{k}$. The initial value of $w_{2}$ is chosen to be 0.15 , which is slightly smaller than that in Deardorff $(1978)(0.20)$.

The initial ground surface temperature, $T_{g}$, is set at $278.5 \mathrm{~K}$, which is the observed temperature at screen height $(1.2 \mathrm{~m})$ at $0900 \mathrm{EST}$ on Day 33. $T_{2}$ is fixed as $284.6 \mathrm{~K}$.

\section{RESULTS AND DISCUSSIONS}

Because the vertical velocity $(\bar{w})$ cannot be calculated in the one-dimensional model, the observed $\bar{w}$ field is used to calculate the vertical advections of temperature and moisture. The observed $w$ from $0900 \mathrm{EST}$, Day 33 to $0900 \mathrm{EST}$, Day 35 are typically of the order of $2 \mathrm{~cm} \mathrm{~s}^{-1}$ before 2000 EST, Day 34 (Fig. 1). After that time, there are strong downward motions at 2100 EST, Day 34 and 0800 EST, Day 35.

a. Temperature and heat flux 


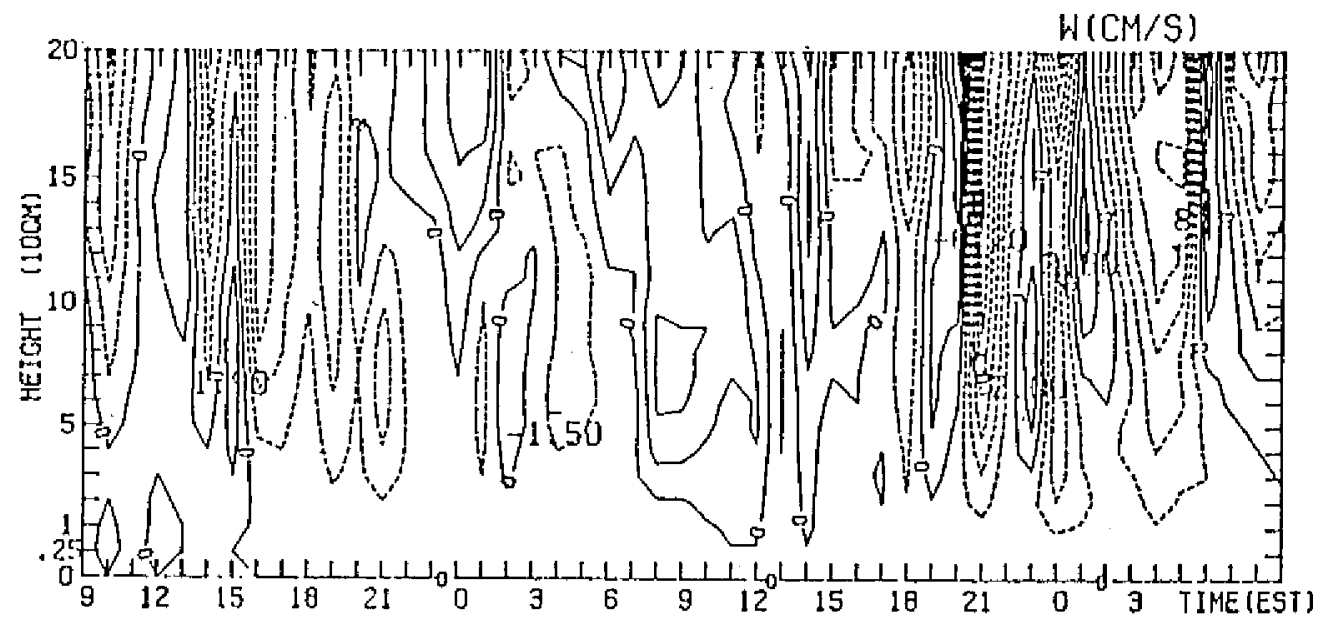

Fig. 1. Hourly variation of the observed vertical velocity $\left(\mathrm{cm} \mathrm{s}^{-1}\right)$ from 0900 EST, Day 33 to 0900 EST, Day 35 in the Wangara Experiment. Contour interval of $1 \mathrm{~cm} \mathrm{~s}^{-1}$.

The computed and observed profiles of the virtual potential temperature during the daytime on Day 33 are expressed in Fig. 2. The model produces a shallow super-adiabatic layer near the ground surface, a deep well-mixed layer in the middle, and an inversion layer atop. Because the heat flux is calculated by the eddy-coefficient method, the model air is slightly unstable in the mixed layer. In general, these profiles are in good agreement with the observed results. That the computed height of inversion at $1200 \mathrm{EST}$ is lower than observed is partly due to the strong downward motion (Fig. 1). This lower computed height of inversion also appears in the moisture fields (Fig. 5). As in Andre et al. (1978) and Yamada and Mellor (1975), the computed temperatures in the mixed layer at 1800 EST are slightly smaller than observed. The computed and observed nocturnal structures of $\bar{\theta}_{v}$ on Day 33-34 are shown in Fig. 3. Due to the strong surface radiative cooling at night, the surface stable layer continuously develops with time in both the computed and observed results. Meanwhile, the thickness of the well-mixed layer decreases with time because of the development of the surface stable layer and the decrease in height of the upper inversion due to the large-scale subsidence. Both the computed and observed temperatures within the surface inversion layer decrease continuously with time due to the long-wave radiative cooling. The long-wave radiative cooling is partially compensated by the adiabatic warming of large-scale subsidence. At 2100 EST and 0000 EST in Fig. 3b, the increase of observed virtual potential temperature at the heights between $200 \mathrm{~m}$ and $700 \mathrm{~m}$ is partially attributed to 

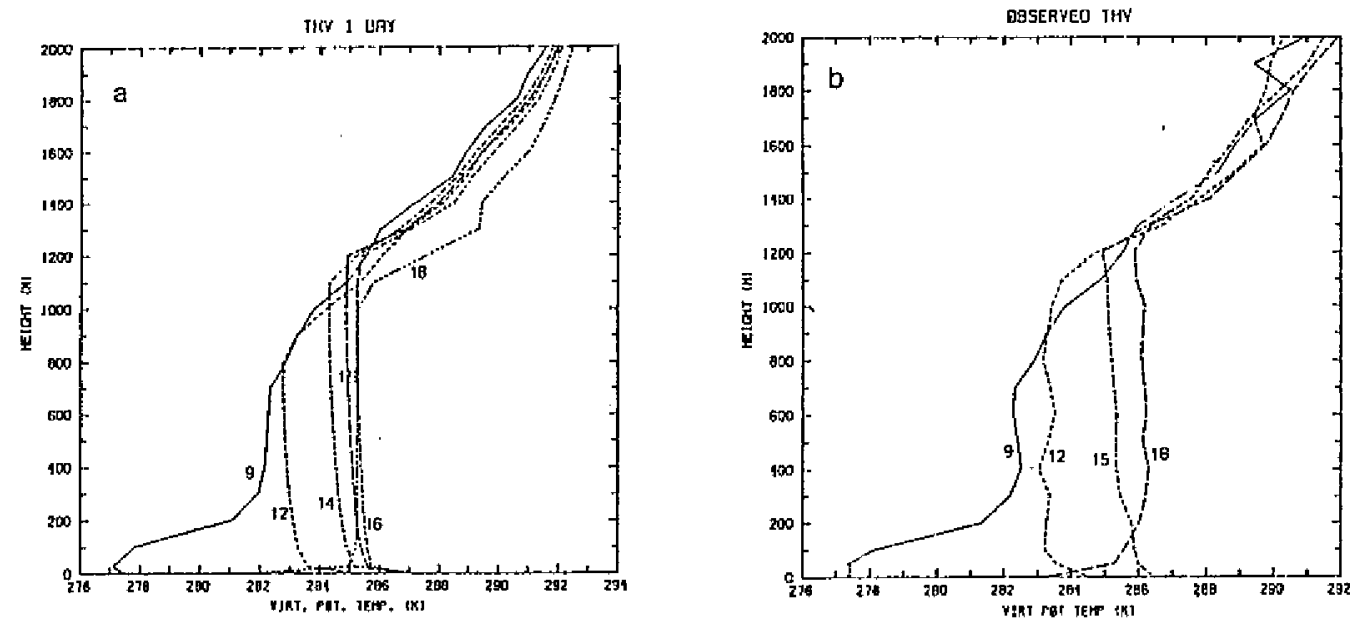

Fig. 2. Vertical profiles of the virtual potential temperature during the daytime on Day 33: (a) computed, (b) observed.
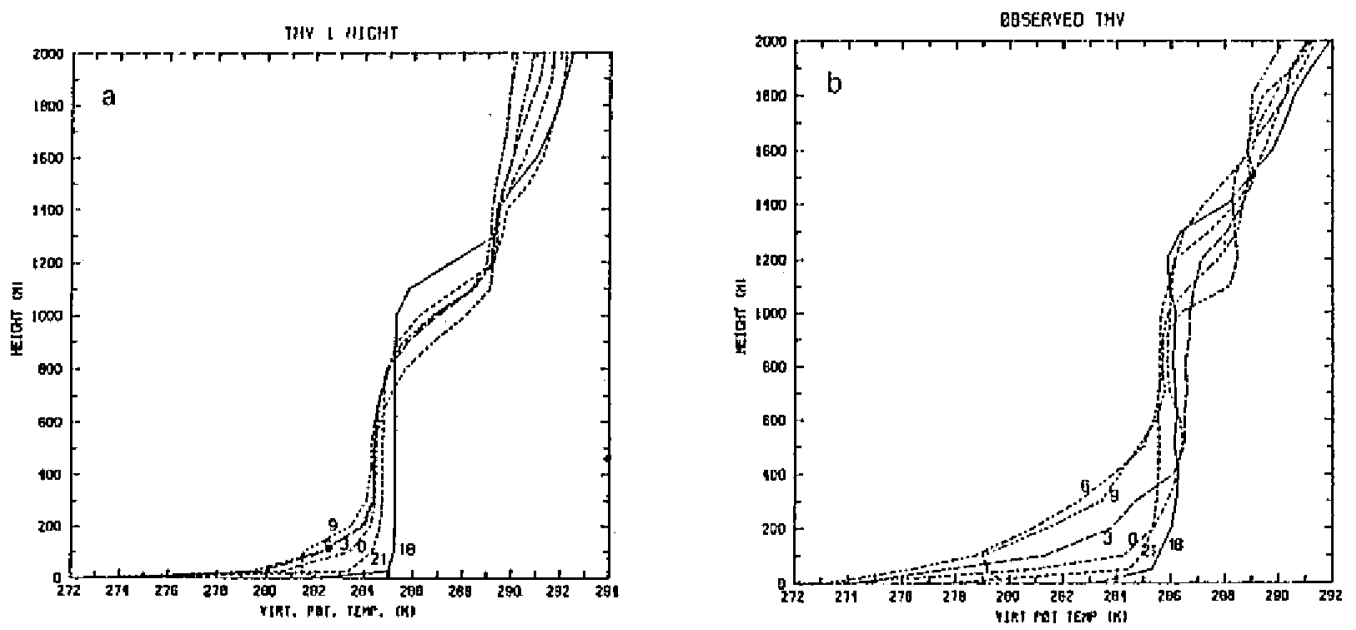

Fig. 3. Same as Fig. 2 except during the night on Day 33-34.

the increase of moisture, which cannot be simulated by a one-dimensinal model.

The height of the observed upper inversion decreases continuously from about $1200 m$ at 1800 EST, Day 33 to about $950 m$ at 0600 EST, Day 34 . Basically, these decreases are captured by our model although the simulated height of the inversion is slightly lower. This discrepancy may be caused by uncertainties in the (observed) downward motion used in calculating the vertical advection terms. The downward motion also retards the growth of the nocturnal inversion.

The vertical profiles of computed heat flux $\left(\overline{w^{\prime} \theta_{v}^{\prime}}\right)$ at $1200,1400,1600$ and 0200 EST on Day 33-34 are presented in Fig. 4. It is noted that the surface heat flux is calculated by the surface budget equation, which is different from 
a specified surface temperature (or heat flux) in Wyngaard and Cote (1974), Yamada and Mellor (1975), Andre et al. (1978), Sun and Ogura (1980), Chen and Cotton (1983a), and Sun and Chang (1986a). In Fig. 4, the vertical heat flux in CBL decreases linearly with height and becomes negative at the inversion. The downward heat flux at inversion height is about 4 to $13 \%$ of the upward surface heat flux. These agree with various simulations such as: 5 to $12 \%$ in Wyngaard and Cote (1974); 4 to $7 \%$ in Sun and Ogura (1980); 4 to $9 \%$ in Sun and Chang (1986a); 14 to $21 \%$ in Deardorff (1974a), 9 to $21 \%$ in Zeman and Lumley (1976). The ratio observed in the atmosphere by Lenschow (1970) is $5 \%$ and that obtained in the laboratory experiments by Willis and Deardorff (1974) is 5 to $8 \%$. At 0200 EST (night), a strong downward heat flux exists near the ground surface due to the strong temperature gradient; above the surface inversion layer, the heat flux is negligible.

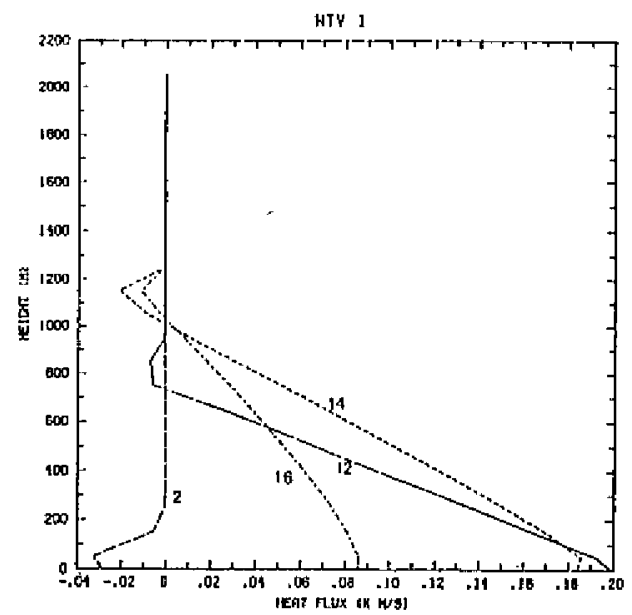

Fig. 4. Profiles of the computed vertical virtual potential temperature flux $\left(\overline{w^{\prime} \theta_{v}^{\prime}}\right)$ at $1200,1400,1600$ EST on Day 33 and 0200 EST in Day 34 .

Like Deardorff's results (1974a), the profiles of heat flux show a slight curvature near the surface due to radiative warming (cooling) caused by the warm (cool) ground surface. Therefore, the heat fluxes in our model are consistent with earlier calculations and measurements, even though the surface temperature is simulated by the prognostic equation in this study.

b. Moisture and moisture flux

Fig. 5 shows the computed and observed profiles of total specific humidity $\left(\bar{q}_{w}\right)$ during the daytime on Day 33. The humidity is well mixed in the mixed layer. There is a small, but persistent, decrease with altitude in both simulated 
and observed curves due to the rapid growth of the mixed layer into the very dry air aloft (Andre et al., 1978). When the mixed layer grows, the surface moisture supply is not large enough to maintain the early morning mixing ratio near the ground surface. Therefore, both the computed and observed humidity in the mixed layer decrease with time. Due to the large-scale subsidence at the upper layer, the top of the well-mixed humidity at 1800 EST decreases to the height of $1000 \mathrm{~m}$ (Fig. 5a), which is lower than the observed results. In the observed profiles, the effects of subsidence on the humidity are partially compensated for by horizontal advection, which is not included here. the depth of the calculated mixed layer is lower than the observed mainly because of a strong subsidence used in this model.
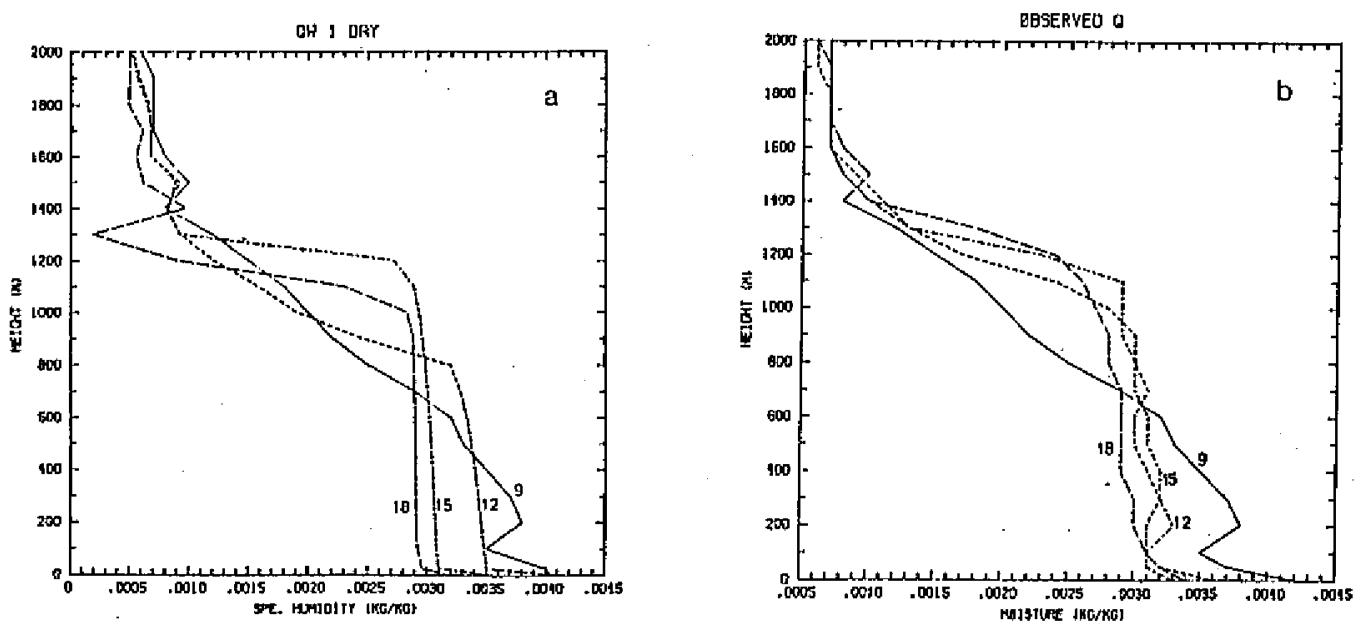

Fig. 5. Profiles of the specific humidity $\left(\bar{q}_{w}\right)$ during the daytime in Day 33:

(a) computed, (b) observed.

The observed $\bar{q}_{w}$ between 100-300 $m$ increased rapidly during the night on Day 33-34 due to a strong moisture advection, which is not included in our model. Hence, we will not present the comparison between the simulated and observed profiles.

The vertical profiles of computed moisture fluxs $\left(\overline{w^{\prime} q_{w}^{\prime}}\right)$ at 1200,1500 , and 1800 EST on Day 33 (Fig. 6) are similar to those in Deardorff (1974a), Andre et al. (1978), and Sun and Ogura (1980). It is noted that in this study the surface moisture fluxes are calculated from the budget equation for water content at the surface, instead of a given function used in Sun and Ogura and others.

\section{c. Winds}

The time variation of the simulated and observed profiles of $\bar{u}$ and $\bar{v}$ during the Day 33-35 are presented in Figs. 7 and 8. The nocturnal low-level jets 


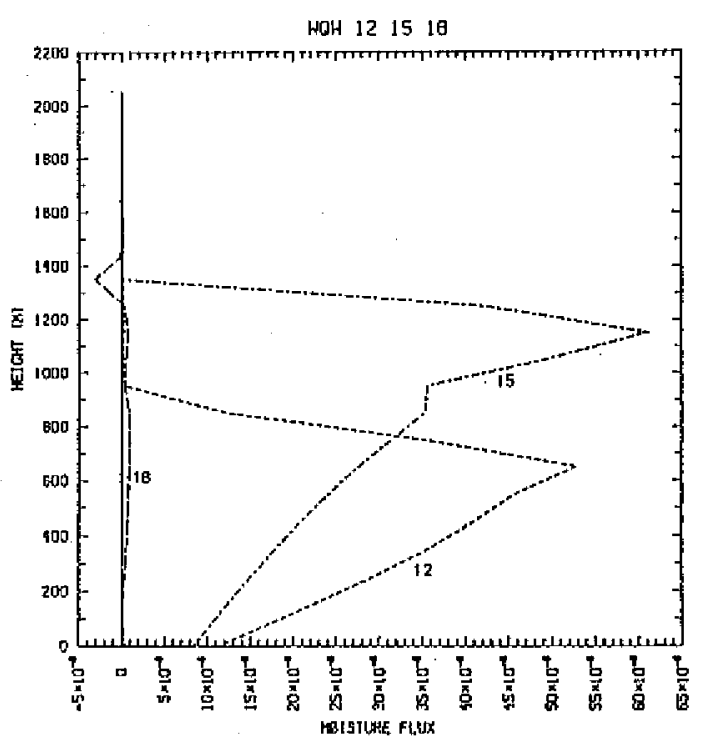

Fig. 6. Profiles of the computed moisture flux $\left(\overline{w^{\prime} q_{w}^{\prime}}\right)$ at 1200,1500 , and 1800 EST on Day 33 .

are clearly shown in both observation and simulation, although the observed wind speed is slightly stronger. During the daytime, wind is much weaker due to strong convection in the CBL. After sunset, the boundary layer becomes stable and the momentum flux is negligible. As a result of inertial oscillation, the nocturnal low-level jet can subsequently develop (Blackadar, 1957). The simulated wind is also in agreement with Yamada and Mellor (1975) and Andre et al. (1978). It is also noted that the observed wind is more irreqular than simulations. The discrepancy between the computed and observed winds has also appeared in the results of Deardorff (1974a), Yamada and Mellor (1975), Andre et al. (1978), Sun and Ogura (1980), Sun and Chang (1986a). The main cause may be the use of an inaccurate geostrophic wind in the momentum equations. It may also be caused by inappropriate treatment of the momentum fluxs, or neglect of the horizontal advection of momentum as discussed by Sun and Chang (1986a). Also, as mentioned previously, the use of free boundary conditions at the top may cause the discrepancy between the computed and observed winds, especially in the upper layer.

\section{d. Budget of the turbulent kinetic energy}

The budget of turbulent kinetic energy (TKE) at 1500 EST in Day 34 (Fig. 9) is close to those obtained by Sun and Chang (1986a), and Andre et al. (1978). The dissipation rate $(D)$ and the buoyant production $(B)$ are the dominant terms. They almost compensate each other in the mixed layer expect near 

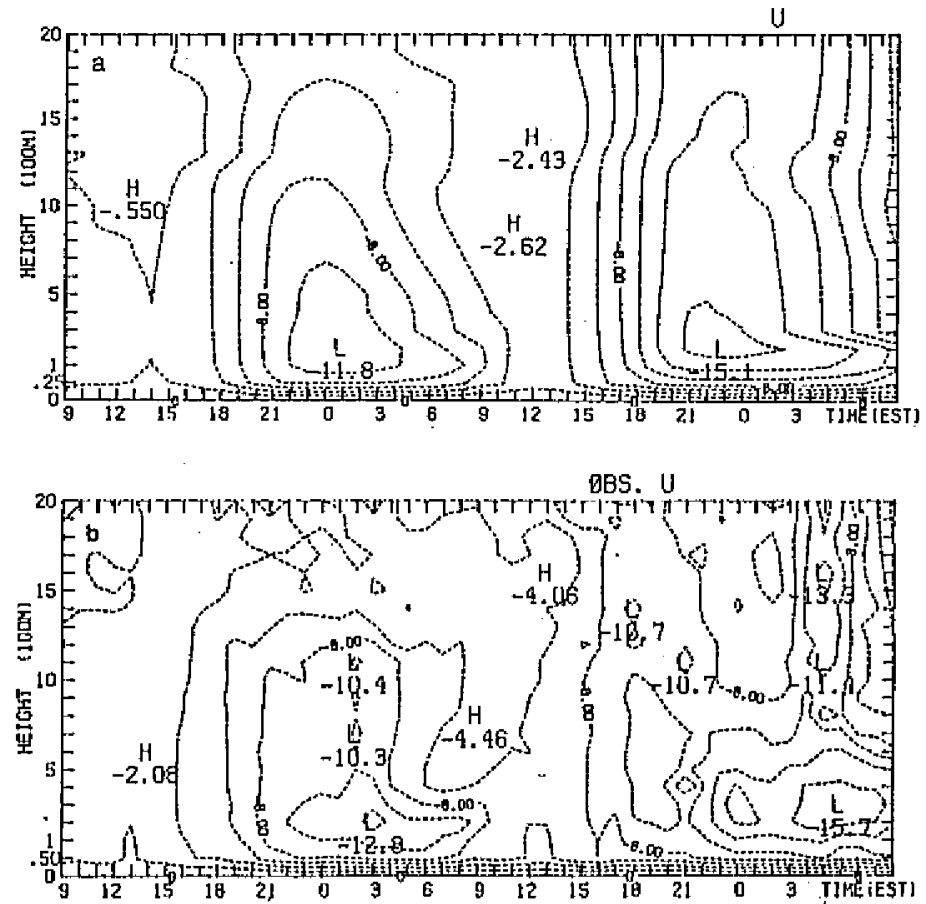

Fig. 7. The hourly time and space variation of rmean velocity $(\bar{u})\left(m s^{-1}\right)$ from 0900 EST, Day 33 to 0900 EST, Day 35: (a) simulated, (b) observed. Contour interval of $2 \mathrm{~m} \mathrm{~s}^{-1}$
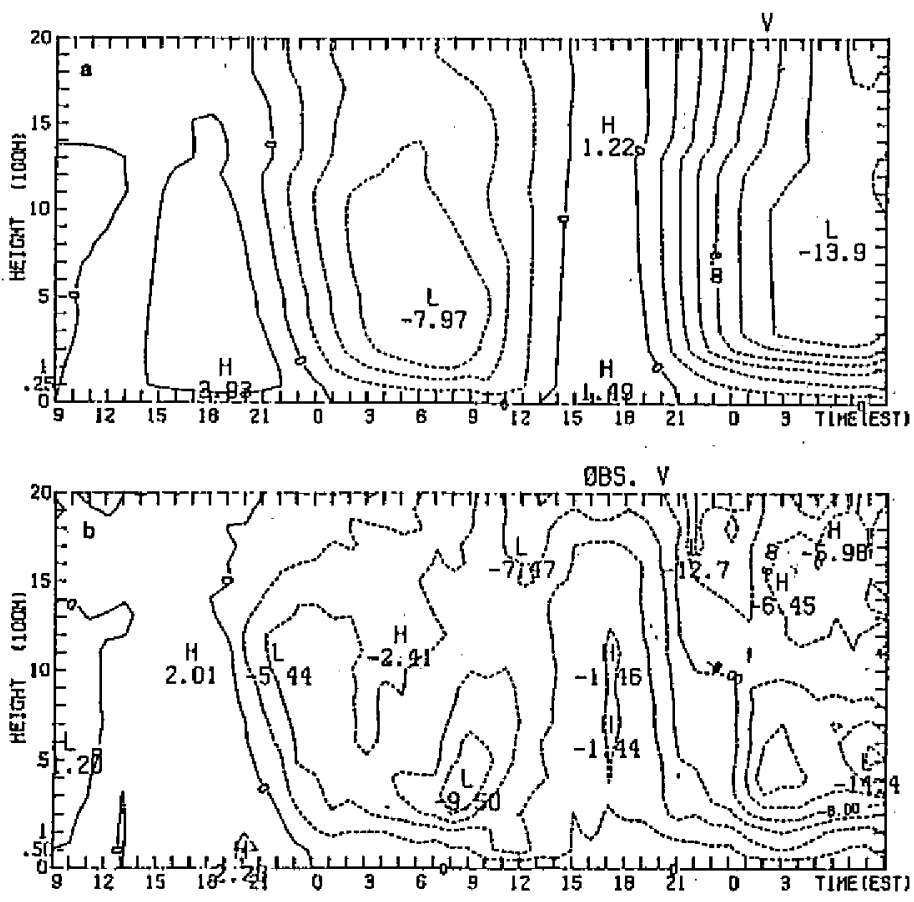

Fig. 8. Same as Fig. 7 expect for $\bar{v}$. 
the surface and the inversion. The transport term $(T)$ is crucial to sustaining TKE against the dissipation and the negative buoyant production at inversion. The turbulent transport term is also important in the lower mixed layer to compensate for a larger dissipation near the ground. The ratio of the transport term at the inversion to the heat flux at ground surface is about $16 \%$ here, which is close to the value of $17 \%$ obtained by Sun and Chang (1986a).

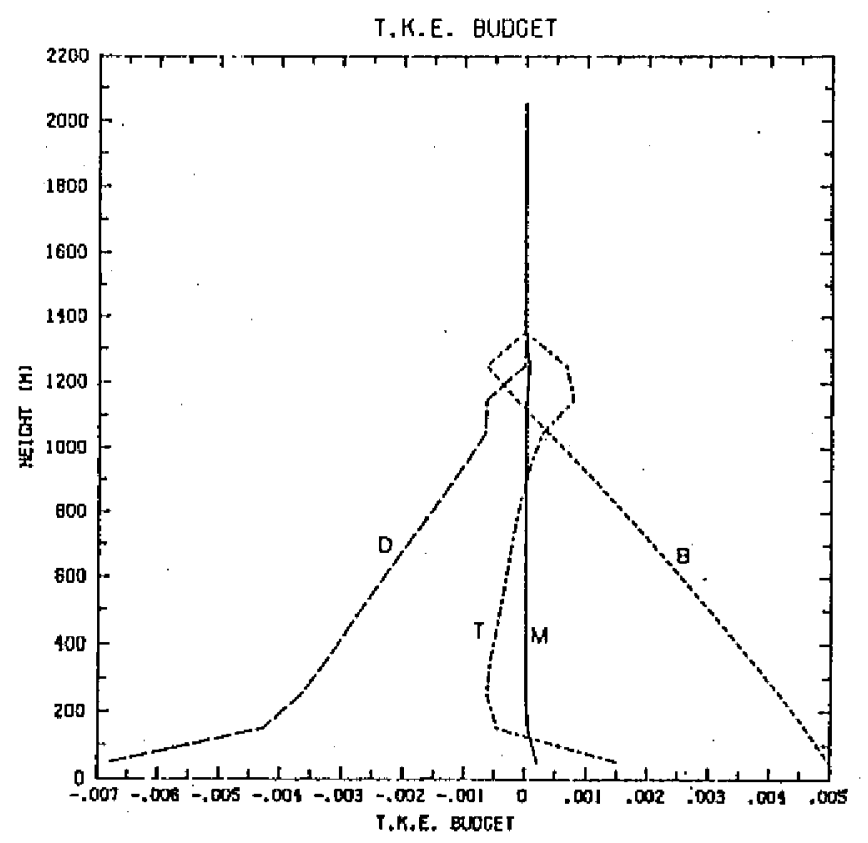

Fig. 9. Budget of the turbulent kinetic energy $\left(m^{2} s^{-3}\right)$ at 1500 EST, Day 34: $\mathrm{B}$, buoyancy production; $\mathrm{T}$, transport term; $\mathrm{D}$, dissipation term; $\mathrm{M}$, shear production.

It is well recognized that the scaling proposed by Deardorff (1970) can produce a universal profile of the trubulence parameter in the convective boundary layer. Following his arguments, the convective velocity $w_{*}$ is defined as

$$
w_{*}=\left[g\left(-u_{*} \theta_{*}\right) z_{i} / \theta_{0}\right]^{\frac{1}{3}}
$$

where $z_{i}$ is the depth of the mixed layer, $u_{*}$ is frictional velocity, and $\theta_{*}$ is temperature scale. The calculated dimensionless TKE at 1300 EST, Day 33 is represented in Fig. 10. The figure also includes the laboratory experimental data by Wills and Deardorff (1974), Enger (1983), and the numerical simulation results of other models. 


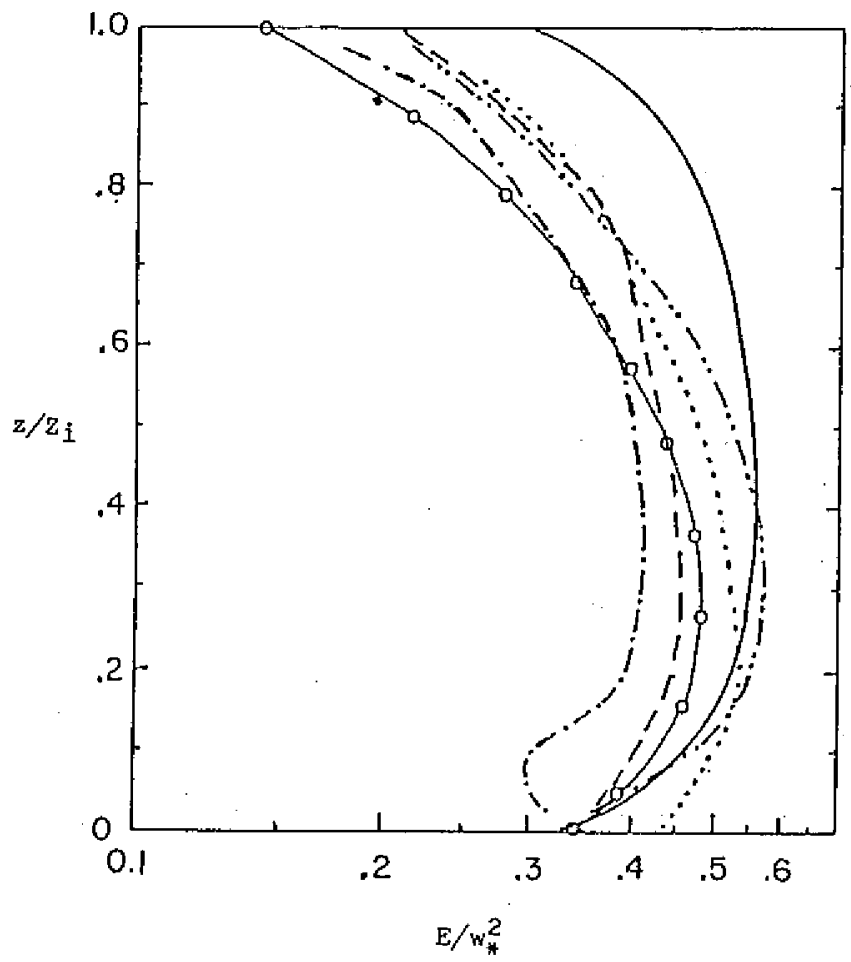

Fig. 10. Dimensionless turbulent kimetic energy $\left(E / w_{*}^{2}\right)$ : solid line, (Enger, 1983, eq.); dashed line, Willis and Deardorff's (1974) laboratory experiment; dashed-dotted line, Andre et al. (1978); dotted line, Enger (1983); dashed-dotteddotted-dashed line, Sun and Chang (1986a); circle-solid line, present study.

\section{e. Radiative cooling rate}

The computed long- and short-wave radiative cooling/warming rates at 1500 EST, Day 33 and 0300 EST, Day 34 are presented in Fig. 11. At 1500 EST, the average short-wave radiative warming rate is about $0.026 \mathrm{~K} \mathrm{hr}^{-1}$ (range from 0.017 to $0.052 \mathrm{~K} \mathrm{hr}^{-1}$ ), which is close to the results in Lacis and Hansen (1974) $\left(\sim 0.75 \mathrm{Kday}^{-1}\right.$ or $\left.0.031 \mathrm{~K} \mathrm{hr}^{-1}\right)$ below the height of $2000 \mathrm{~m}$. The maximum warming rate $\left(\sim 0.052 K \mathrm{Kr}^{-1}\right)$ appears just above the inversion, where the discontinuity of moisture occurs. It is noted that the short-wave radiative warming rate is a function of the cosine of the solar zenith angle, which has a value of 0.48 in Fig. 11.

Except near the surface, the average long-wave radiative cooling rate at $1500 \mathrm{EST}$ is about $-0.078 K \mathrm{hr}^{-1}$, which is close to the results in Schmetz and Beniston (1986). Because of the hot ground surface, the maximum long-wave radiative warming rate near the surface reaches $0.45 \mathrm{~K} \mathrm{hr}^{-1}$, which is close to the value (about $0.52 \mathrm{~K} \mathrm{hr}^{-1}$ ) used in Deardorff (1974a). On the other hand, 


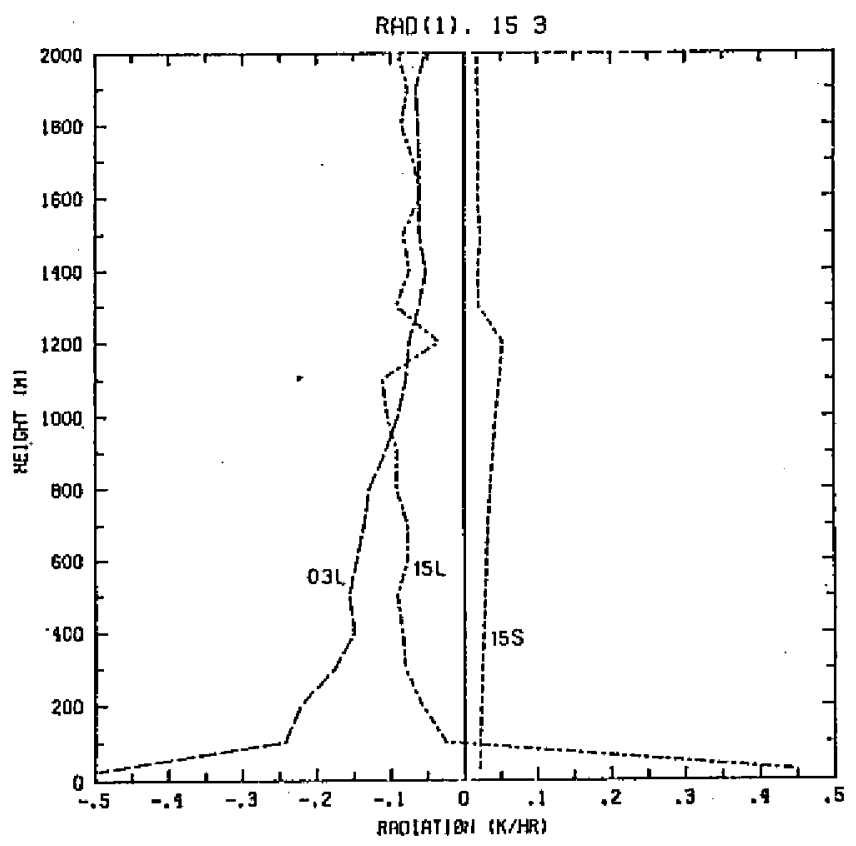

Fig. 11. Vertical profiles of the computed long-and short-wave radiative cooling rate $\left(K h r^{-1}\right)$ at 1500 EST, Day 33 and 0300 EST, Day 34.

at $0300 \mathrm{EST}$, the strong long-wave radiative cooling occurs at the lower layer due to the cool ground surface. The maximum cooling rate at the height of $25 \mathrm{~m}$ can reach $-0.50 \mathrm{~K} \mathrm{hr}^{-1}$.

\section{f. Surface temperature}

Fig. 12 shows the variations of the simulated ground surface temperature $\left(T_{g}\right)$, the simulated screen temperature $\left(T_{1.2}\right)$, and the observed screen temperature $\left(T_{o b s}\right)$, at the height of $1.2 \mathrm{~m}$. The predicted screen temperature, obtained by McNider and Pielke (1981) (circle) is also included. Overall, both simulated temperatures are very close to the observed one. However, our model is simpler than McNider and Pielke's, which included multiple layers to calculate the soil temperature. The diurnal oscillation of the surface temperature is well simulated. Both maxima of $T_{o b s}$ and $T_{1.2}$ lag that of $T_{g}$ by about 1-2 hours on Day 34. The sudden warming of $T_{o b s}$ between $2300 \mathrm{EST}$, Day 34 and $0300 \mathrm{EST}$, Day 35 is not captured by the model, which may be associated with a warm and moist advection near the surface. However, at 0900 EST on Day 35 (after 48 hours simulation), the predicted screen temperature is close to the observed screen temperature. 


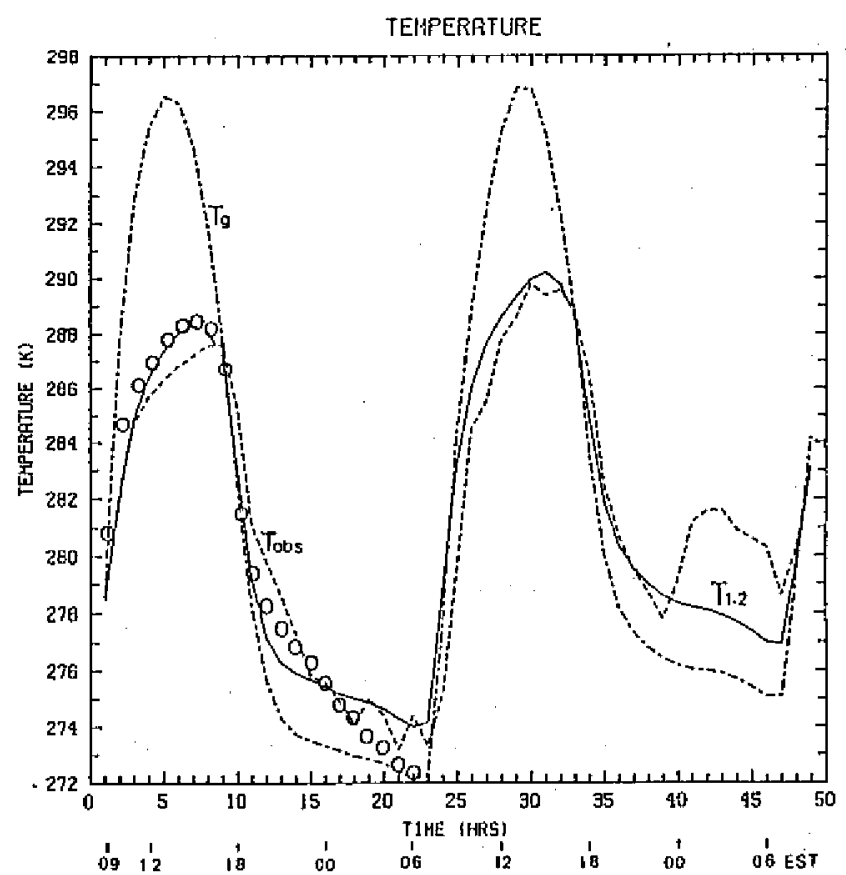

Fig. 12. Hourly variations of the temperature: dashed-dotted line, predicted surface soil temperature $\left(T_{g}\right)$; sold line, predicted temperature $\left(T_{1,2}\right)$ at screen height $(1.2 \mathrm{~m})$; dashed line, observed temperature $\left(T_{o b s}\right)$ at screen height; circle, predicted screen temperature in McNider and Pielke (1981).

\section{SUMMARY}

An ensemble average turbulence model, including radiation and surface energy balance equations, is applied to study the evolution of the planetary boundary layer for cloud-free situations. In addition to equations these govern equivalent potential temperature, specific humidity, and the two horizontal wind components, a prognostic equation is used to calculate the turbulent kinetic energy. the eddy-coefficient relations in Deardorff (1980) and Sun and Chang (1986a) are employed to calculate the eddy fluxes. The lengh scales in Sun and Ogura (1980) and Deardorff (1980) are modified and used in this study.

Through the surface energy balance equation, the ground surface soil temperature is predicted by a force restoring method (Bhumralkar, 1975; Blackadar, 1976; Deardorff, 1978). An analogous method is used to predict the surface soil moisture (Deardorff, 1978).

Rodgers' (1967) parameterization for long-wave radiation, Yamamoto's (1962 ) parameterization for absorption of short-wave radiation, and Stephens' method (Chen and Cotton, 1983b) for the Rayleigh scattering are utilized in the cloud- 
free atmosphere.

The model is used to simulate the observed data on Day 33-35 in the Wangara Experiment. The profiles of computed wind, moisture, and temperature compare well with the results of observations and other models. The variations of the predicted surface soil temperature are consistent with the observed temperature at the screen height. Also, the second moments agree well with those obtained by the other higher-order closure models.

Acknowledgements. Part of this work was supported by the National Science Council and the National Science Foundation (U.S.A.) under grants ATM8313418 and 8611729

\section{REFERENCES}

Andre, J. C., G. DeMoor, P. Lacarrere and G. Therry and R. duVachat, 1978: Modeling the 24 hour evolution of the mean and turbulent structures of the planetary boundary layer. J. Atmos. Sci., 35, 1861-1883.

Bhumralkar, C. M., 1975: Numerical experiments on the computation of ground surface temperature in an atmospheric general circulation model. J. Appl. Meteor., 14, 1246-1258.

Blackadar, A. K., 1957: Boundary layer wind maxima and their significance for the growth of nocturnal inversion. Bull. Amer. Meteor. Soc., 38, 283-190.

, 1976: Modeling the nocturnal boundary. Proceedings of the Third Symposium on Atmospheric Turbulence, Diffusion and Air Quality, 46-49, Amer. Meteor. Soci..

Businger, J. A., J. C. Wyngaard, Y. Izumi and E. F. Bradley, 1971: Fluxprofile relationships in the atmospheric surface layer. J. Atmos. Sci., 28, 181-189.

Caughey, S. J., B. A. Crease, and W. T. Roach, 1982: A field study of nocturnal stratocumulus. Part II: Turbulent structure and entrainment. Quart. J. Roy. Meteor. Soc., 108, 125-144.

Chen, C., and W. R. Cotton, 1983a: Numerical experiments with a onedimensional higher order turbulence model: simulation of the Wangara Day 33 case. Bound. - Layer Meteor., 25, 375-404.

and ___, 1983b: A one-dimensional simulation of the stratocumulus-capped mixed layer. Bound.-Layer Meteor, 25, 289-231.

Clark, R. H., D. G. Reid and A. J. Troup, 1971: The Wangara experiment: Boundary layer data. Tech. paper 19. Div. Meteor. Phys, CSIRO, Australia.

Deardorff, J. W., 1970: Convective velocity and temperatures scales for the 
unstable planetary boundary and for Rayleigh convection. J. Atmos. Sci., 27, 1211-1213.

, 1974a: Three-dimensional numerical study of the height and mean structure of a heated planetary boundary layer. Bound.-Layer Meteor., 7, 81-106.

, 1974b: Three-dimensional numerical study of turbulence in an entraining mixed layer. Bound.-layer Meteor., 7, 199-226.

, 1978: Efficient prediction of ground surface temperature and moisture, with inclusion of a layer of vegetation. J. Geophysical Res., 83, 1889-1903. , 1980: Stratocumulus-capped mixed layers derived from a three-dimensional model. Bound.-Layer Meteor., 18, 495-527.

Enger, L., 1983: Numerical boundary layer modeling with application to diffusion. Part I: A two dimensional higher order closure model. Dept. of Meteor., University of Uppsala, Sweden, Report No.70, 54pp.

Lacis, A. A. and J. Hansen, 1974: A parameterization for the absorption of solar radiation in earth's atmosphere. J. Atmos. Sci, 31, 118-133.

Lenschow, D. W., 1970: Airplane measurements of planetary boundary layer structure. J. Appl. Meteor., 9, 874-884.

McNider, R. T., and R. A. Pielke, 1981: Diurnal boundary-layer development over sloping terrain. $J$ : Atmos. Sci., 38, 2198-2212.

Mellor, G. L., and T. Yamada, 1977: A turbulence model applied to geophysical fluid problems. Proceedings Symposium on Turbulent Shears Flows. Penn. State Univ. 1-14.

Oliver, D. A., W. S. Lewellen and G. G. Williamson, 1978: The interaction between turbulent and radiative transport in the development of fog and low-level stratus. J. Atmos. Sci., 35, 301-316.

Rodgers, C. D., 1967: The use of emissivity in atmosphreic radiation circulations. Quart. J. Roy. Meteor. Soc., 93, 43-54.

Schmetz, J. and M. Beniston, 1986: Relative effects of solar and infrared radiative forcing in a mesoscale model. Bound.-Layer Meteor., 34, 137-155.

Stephens, G. L., 1978: Radiation profiles in extended water clouds. Part II: Parameterization scheme. J. Atmos. Sci., 35, 2123-2132.

Sun, W. Y., 1989: Diffusion modeling in a convective boundary. Atmos. Envirn., 23, 1205-1217.

, and C. Z. Chang, 1986a: Diffusion model for a convective layer: Part 1. Numerical simulation of a convective boundary layer. J. Climate and Appl. Meteor., 25, 1445-1453.

, and__ 1986b: Diffusion model for a convective layer: Part 2. Plume released from a continuous point source. J. Climate and Appl. Meteor., $25,1454-1463$. 
and W. -R, Hsu, 1988: Numerical study of cold air outbreak over warm ocean. J. Atmos. Sci., 45, 1205-1227.

, and Y. Ogura, 1980: Modeling the evolution of the convection planetary boundary layer. J. Atmos. Sci., 37. 1558-1572. , and Yilidrim, 1989: Air mass modification over Lake Michigan. Bound.Layer Meteor., 48, 345-360.

Willis, G. E., and J. W. Deardorff, 1974: A laboratory model of the unstable planetary boundary layer. J. Atmos. Sci., 31, 1297-1307.

Wu, C. C., and W. Y. Sun, 1987: Formation and evolution of dryline. Third Conference on Mesoscale Meteorology, Vancouver, Canada, 222-223.

Wyngaard, J. C., 1975: Modeling the planetary boundary layer-Extension to the stable case. Bound.-Layer Meteor., 9, 441-461.

, and O. R. Cote, 1974: The evolution of the convective planetary boundary layer-a higher-order closure model study. Bound.-Layer Meteor., $\mathbf{7}, 289$ 308.

Yamada, T., and G. L. Mellor, 1975: A simulation of the Wangara atmospheric boundary layer data. J. Atmos. Sci., 32, 2309-12329.

, and __ 1979: A numerical simulation of BOMEX data using a turbulence closure model coupled with ensemble cloud relations. Quart. J. Roy. Meteor. Soc., 105, 915-944.

Yamamoto, G., 1962: Direct absorption of solar radiation by atmospheric water vapor, carbon dioxide and molecular oxygen. J. Atmos. Sci., 19, 182-188.

Zeman, O, and J. L. Lumley, 1976: Modeling buoyancy driven mixed layers. J. Atmos. Sci., 33, 1974-1988.

and___, 1978: Buoyancy effects in entraining turbulent boundary layers: a second-order closure study. Proceedings of Symposium on turbulent shear flows, Springer Verlag. 


\title{
對流邊界層之日夜變化 第一部分 無雲大氣
}

\author{
吳清吉 \\ 國立台灣大學大氣科學系 \\ 商文義 \\ 美國普度大學地球和大氣科學系
}

摘 要

一個簡單的一䊒總體平均漫界層模式, 用以研究無雲大氮時邊界船的演化。模式中包含

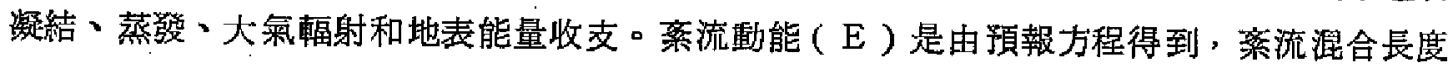
、尺度 $(\ell)$ 則由 Sun 與Ogura 和Deardorff 的方法修颌得到; 累流察數正比於 $\ell \sqrt{\mathrm{E}}$ 。地面曆則使用 Businger et. al. 所建議的相似方程式。此外, 強迫恢復方法也被利用於 預報地表的溫度和濕度。

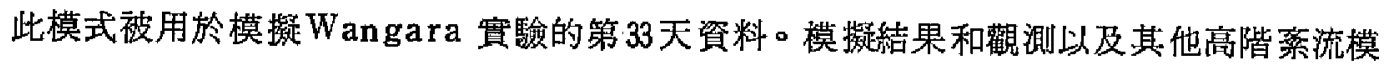
式的結果比較, 相䓨的一致。 